\title{
Does Sterilization Affect the Push Out Bond Strength of Experimental Dentin Posts?
}

\section{¿Afecta la esterilización la fuerza de adherencia de los postes de dentina experimentales?}

Ayça Tulga DDS, PhD; Fatma Ayşe Şanal DDS, PhD²; Doğu Ömür Dede DDS, PhD³

1. Department of Prosthodontics, Faculty of Dentistry, Ordu University, Ordu, Turkey.

2. Department of Prosthodontics, Faculty of Dentistry, Bolu Abant Izzet Baysal University, Bolu, Turkey.

3. Department of Prosthodontics, Faculty of Dentistry, Ordu University, Ordu, Turkey.

Correspondence to: Dr. Ayça Tulga - aycaerkocak@hotmail.com

\section{ABSTRACT}

The purpose of this preliminary study is to evaluate the push-out bond strength (PBS) of experimental dentin posts (EDPs) obtained from human and bovine teeth sterilized by autoclaving and gamma radiation. Eighty-four mandibulary premolars were obturated and divided into three post groups: the glass fiber group (Fb) human EDP group ( $\mathrm{Hm}$ ) and the bovine EDP group (Bv). Three subgroups $(\mathrm{n}=12)$ were obtained for each EDP groups according to the sterilization methods; no sterilization (Cnt), steam autoclaving (Aut), and gamma radiation (Rad) a total dose of $25 \mathrm{kGy}$. All posts were cemented to root canals using a dual cured resin cement (Panavia SA). After the micro slices (1 mm in thickness) were obtained of each subgroup, PBS test was performed. Data were analyzed using two-way ANOVA and Tukey's multiple comparison tests $(\alpha=.05)$. The post type and sterilization method was significantly effective on the PBS values according to the ANOVA ( $\mathrm{P}<.001)$. No sterilization apllied EDP groups showed significantly higher PBS values than the sterilized groups $(\mathrm{P}<.001)$. Bv_Cnt $(9.42 \pm 1.31)$ showed significantly lower PBS values than both $\mathrm{Fb}(12.36 \pm 1.54)$ and $\mathrm{Hm} \_\mathrm{Cnt}(11.06 \pm 1.38)$ groups $(\mathrm{P}<.001)$. Both steam autoclaving and gamma radiation affect the PBS values and fracture modes of EDPs negatively. The bovine EDPs are not as effective as human EDPs with regard to the PBS to the root dentin.

\section{KEYWORDS}

Dentin post; Gamma radiation; Steam autoclaving; Push-out bond strength. 


\section{RESUMEN}

El propósito de este estudio preliminar es evaluar el push-out bond strength de los postes de dentina experimentales (PDE) obtenidos de dientes humanos y bovinos esterilizados por autoclave y radiación gamma. Ochenta y cuatro premolares mandibulares fueron obturadores y se dividieron en tres grupos experimentales de postes: el grupo de fibra de vidrio (Fb) grupo PDE humano ( $\mathrm{Hm}$ ) y el grupo PDE bovino (Bv). Se obtuvieron tres subgrupos $(n=12)$ para cada grupo de PDE según los métodos de esterilización; sin esterilización (Cnt), autoclave a vapor (Aut) y radiación gamma (Rad) con una dosis total de 25 kGy. Todos los postes se cementaron a los conductos radiculares utilizando un cemento de resina de curado doble (Panavia SA). Después de que se obtuvieron las micro rebanadas (1 $\mathrm{mm}$ de espesor) de cada subgrupo, se realizó una prueba de push-out bond strength. Los datos se analizaron utilizando ANOVA de dos vías y las pruebas de comparación múltiple de Tukey $(\alpha=.05)$. El tipo de poste y el método de esterilización fueron significativamente efectivos en los valores de push-out bond strength según el ANOVA ( $P<.001)$. Los grupos de PDE no aplicados a la esterilización mostraron valores de push-out bond strength significativamente mayores que los grupos esterilizados $(p<0,001)$. Bv_Cnt (9.42 \pm 1.31$)$ mostró valores de push-out bond strength significativamente más bajos que los grupos $\mathrm{Fb}(12.36 \pm 1.54)$ y $\mathrm{Hm} \_\mathrm{Cnt}(11.06 \pm 1.38)(\mathrm{P}<.001)$. Tanto el autoclave al vapor como la radiación gamma afectan negativamente los valores de push-out bond strength y los modos de fractura de los PDE. Los PDE bovinos no son tan efectivos como los PDE humanos con respecto a la fuerza de adhesión a la dentina de la raíz.

\section{PALABRAS CLAVE}

Poste de dentina; Radiación de gama; Autoclave al vapor; Push-out bond strength.

\section{INTRODUCTION}

It has been revealed in recent studies that natural tooth fragments can be used as dentin posts with resilience comparable to that of the original tooth, extremely good adhesion to the dental structure and composite resin, and low cost (as dentin posts are made from donated extracted natural teeth) (1-5). Moreover, the use of dentin posts has reported successful outcomes in related clinical studies $(4,5)$. In conservative dentistry, minimally structure removing is one of the main approaches in root canal preparation for post material (6). Because there is no post material better than a dentin structure for restoration. Therefore, the biological dentin posts are suitable to restorate ETT with advantages of reducing stresses in the remaining root and distributing masticatory loads homogenously over the entire bonded interface. Moreover, biological dentin posts must the best choice for esthetic approaches owing to similar optical properties to the remaining tooth structure in prosthodontic dentistry. There is limited information about the biological dentin posts and this studies have generally compoared the fracture resistance of ETT restored with different post materials. Therefore, further studies are needed to evaluate the physical properties of dentin posts such as bond strength to root dentin.

Bovine-derived graft materials such as xenografts, fetal serum, and inorganic bone, have been widely used in dental surgery $(7,8)$. However, in the restorative dental field, bovine teeth have only been used as a substitute for human teeth in in vitro dental studies (9). Bovine teeth are easy to obtain in large quantities in good condition, and the permeability of bovine dentin is six to 
eight times less than that of human dentin (10). Therefore, bovine teeth fragments can also be used as biological dentin posts, but only after converted into a more biocompatible form.

The sterilization process of extracted human teeth has some difficulties due to destruction or changing of the teeth structure $(11,12)$. Experimental dentin posts (EDPs) need to be sterilized in a way that does not alter the structure of the material. Clinical studies on biological dentin posts generally used autoclaving (at $121^{\circ} \mathrm{C}$ ) for sterilization $(4,5)$. Gamma radiation can be an alternative sterilization method for dentin posts, which has been indicated with no significant effect on the teeth structure by related studies $(13,14)$. However, the effects of autoclaving and gamma radiation on the bonding capacity of biological dentin posts has not been compared in previous studies. Therefore, the aim of this preliminary study is to evaluate the push out bond strength (PBS) of EDPs obtained from human and bovine teeth sterilized with autoclaving and gamma radiation. The following null hypotheses were proposed: (A) there is no difference between EDPs and glass fiber posts (GFP) with regard to PBS and (B) sterilization with gamma radiation and autoclaving does not affect the PBS of dentin posts.

\section{MATERIALS AND METHODS}

The approval for this study was given by the Ethics Committee of Ordu University (\#82678388/31). Eighty-four freshly extracted human mandibulary permanent premolars with similar anatomic crown sizes at cementoenamel junction (CEJ) (mesiodistally and buccolingually) were selected and reduced to a standardized root length $(13 \mathrm{~mm})$ from the coronal aspect using a water cooled diamond saw at a low speed cutting machine (Isomet 1000; Buehler). All the teeth used in this study were stored in $0.5 \%$ chloramine in water at $40 \mathrm{C}$ throughout the study.
Root canal preparation was performed using a step-back technique to a master apical file size of 60 (Colorinox K File; Dentsply Maillefer) at a working length (1 $1 \mathrm{~mm}$ from the apical foramen). Between the use of each instrument, the root canals were irrigated using $2 \mathrm{~mL} 5.25 \%$ sodium hypochlorite ( $\mathrm{NaOCl}$ ) and $5 \mathrm{~mL}$ of $17 \%$ ethylenediaminetetraacetic acid (EDTA). After the final irrigation with distilled water and drying using paper points (Diadent; Diadent Group International), obturation of root canals were performed with gutta-percha (Protaper Universal Gutta Percha Points; Dentsply Maillefer) and AH Plus endodontic sealer (Dentsply; DeTrey) by using the lateral condensation technique. Subsequently, the ETT specimens were mounted in auto polymerized acrylic resin blocks $(10 \mathrm{~mm}$ diameter and $15 \mathrm{~mm}$ height).

The EDPs were prepared using 20 single-root bovine teeth and 20 human maxillary permanent central incisors, which had been extracted for periodontal reasons and stored in 0.5\% chloramine in water at 40C. A low-speed, watercooled diamond saw was used to decoronate each tooth at a level $5 \mathrm{~mm}$ incisal to the labial CEJ and to longitudinally section each in half along the root canal. Therefore root dentin fragments were obtained for EDPs and these root fragments were prepared using water-cooled diamond burs to form cylindrical dentin blocks. The coronal side of each cylindrical dentin fragment was then adhered vertically to a computer aided designcomputer aided manufacturing (CAD-CAM) block holder (Cercon Base; DuguDent GmbH) using a cyanoacrylate adhesive (Zap-It; DVA).

The desired dimensions (diameter $1.5 \mathrm{~mm}$, length $15 \mathrm{~mm}$ ) for the EDPs, similar to those of a GFP (\#3 Cytec Blanco; Hahnenkratt GmbH), were modeled using a CAD software (5 Series; Dental Wings). Milling was conducted according to this CAD model to produce 78 dentin posts of a standardized shape and size. This was done using a three-axis 
computer numerical control milling machine (which possesses $x, y$, and $z$ axes for milling movements) (Yena D40 3R-system; Yenadent Ltd Sti) at a cycle speed reduced to 20,000 rpm (Figure 1,2).

The EDPs were randomly divided into six groups, after the fabrication procedures. Total of seven groups $(n=12)$ were designated as shown in Table 1.

For the restoration of the ETT with the dentin post specimens, the post space (length $8 \mathrm{~mm}$ ) was prepared using a Peeso reamer drill (Mani Inc; Tochigi) to remove gutta-percha from the root canals, leaving only a 4-mm apical root filling intact. Subsequently, tapered drills of the post kit (Cytec Blanco; Hahnenkratt GmbH) between numbers 1 and 3 were used sequentially to enlarge the root canals for post placement. After the preparation of the post spaces, irrigation with $0.2 \%$ chlorhexidine, rinsing with water and drying with paper points were performed respectively. Post cementation was done using a dual-cure self-adhesive resin cement (Panavia SA cement plus; Kuraray Noritake Dental Inc) according to the manufacturer's instructions. Following this, the specimens were stored at $37^{\circ} \mathrm{C}$ and $100 \%$ humidity for 7 days.

To prepare for the push-out test, a watercooled precision saw was used to section each root specimen transversally from coronal to apical in order to obtain three 1-mm-thick samples (coronal, medial and apical samples). The first $0.5 \mathrm{~mm}$ thick section of each root specimen was discarded. Loading was applied to the EDP using a custom stainless steel cylindrical plunger connected to a universal testing machine's load cell (AGS X; Shimadzu Corp.). Push-out force was applied at a cross-head speed of $1 \mathrm{~mm} /$ min in an apical to coronal direction until bond failure occurred. The bond strength at failure was recorded in megapascals ( $\mathrm{MPa})$. The conversion of newtons (N) to MPa was done automatically by the test machine. Mean value of three samples (coronal, medial and apical samples) was used as a PBS value of one teeth.

After the push out test, the failure modes of the sample surfaces were examined using a stereomicroscope (Leica MZ12.5; Meyer Ins) at a magnification of $\times 20$. They were then grouped into four categories: adhesive (between the dentin and cement; between the post and cement), mixed and cohesive failure.

The sterilized EDP specimen surfaces randomly chosen from each group (total of 6 specimens) examined under a field-emission scanning electron microscope (SEM) (Evo L10; Zeiss); SEM photomicrographs were taken at x2500 and x5000 magnifications for visual inspection.

The PBS results were analyzed by twoway ANOVA and Tukey's multiple comparison test $(\alpha=.05)$. Then the failure-modes were analyzed with Pearson Chi-Square test and the correlation between PBS and fracture modes also compared with Pearson correlation analysis. Statistical assessment of the data were carried out using a statistical software package (SPSS $20.0 \mathrm{~V}$; SPSS Inc.) and evaluated at $\mathrm{P}<.05$ level for all tests.

\section{RESULTS}

According to the results of two-way ANOVA, significant differences in PBS were observed according to the post type and the sterilization method ( $P<.001$ ) (Table 2). The highest PBS values were obtained for Fb post group (12.36 $\pm 1.54)$ which is significantly different from the all other groups $(\mathrm{P}<.001)$ except the Hm_Cnt $(11.06$ \pm 1.38 ). No sterilization applied (Cnt) groups showed higher PBS values than the sterilized groups (Fig. 3). When sterilization methods were compared for the same post groups, significantly higher PBS values obtained for both no sterilization applied $\mathrm{Hm}$ and $\mathrm{Bv}$ post groups $(\mathrm{P}<.001)$. When 
the same sterilization method applied post types were compared; significantly lower PBS values were obtained for Bv_Cnt $(9.42 \pm 1.31)$ and $\mathrm{Bv}_{\text {_ }}$ Aut $(7.97 \pm 0.86)$ groups $(P<.001)$. There was no significant difference observed between the remaining groups $(P>.05)$.

A statistically significant difference was found between the test groups for fracture modes according to Pearson's chi-square test $(P$ $\left.=.006, \chi^{2}=27.689\right)$. When the fracture modes were analyzed, a predominance of adhesive type fractures was observed in the Bv_Rad and $\mathrm{Bv}_{\text {_ }}$
Aut groups. The adhesive failures were occurred between the resin cement and the dentin post. Only the Hm_Cnt group showed a predominance of cohesive type fractures (Table 3). Pearson correlation analyses showed that the coefficient of correlation between PBS and fracture modes was statistically significant $(P<.001, r 2=0.405)$, which means that these two variables were correlated.

The SEM images of sterilized and nonsterilized dentin of the human and bovine teeth were shown in Fig.4. Notable variations were found among the Cnt, Aut and Rad groups.

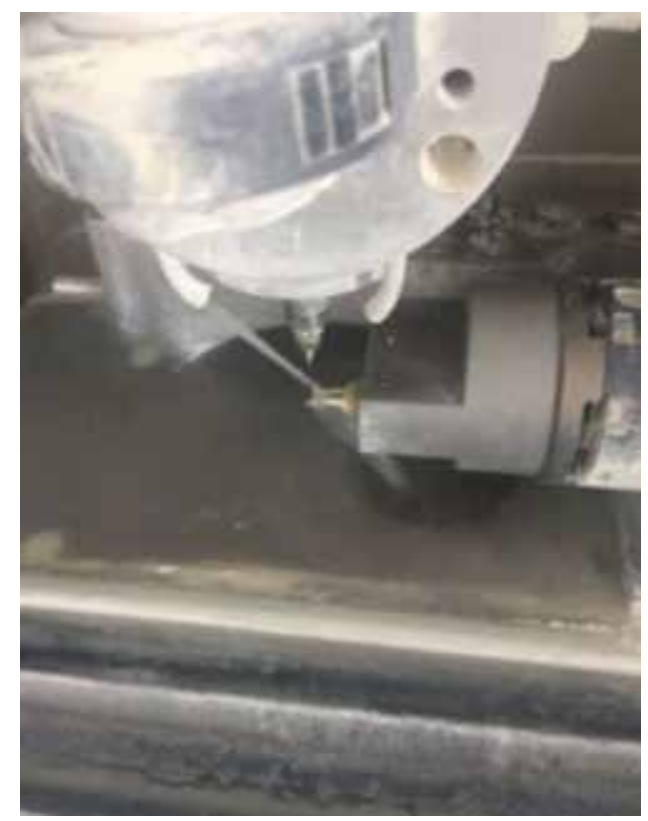

Figure 1.Closer view of dentin fragment being milled in CAD-CAM milling machine to generate dentin post.

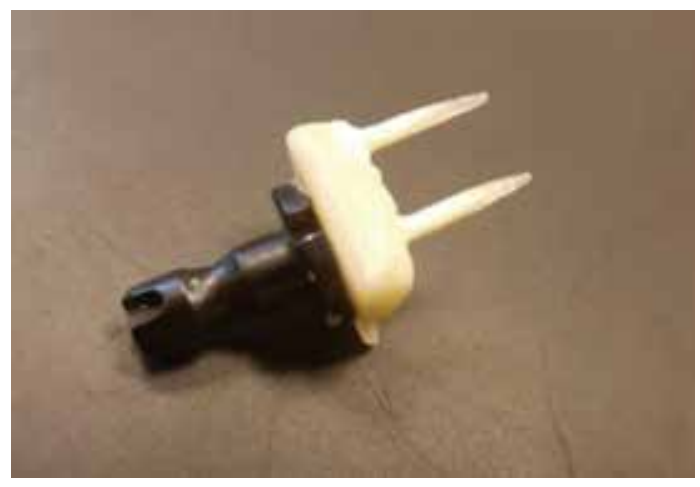

Figure 2. A milled dentin post specimen. 
Table 1. The groups of the present study.

\begin{tabular}{|c|c|c|}
\hline Groups & Post type & Sterilization type \\
\hline $\mathrm{Fb}$ & $\begin{array}{c}\text { GFP } \\
\text { (\#3 Cytec Blanco; Hahnenkratt GmbH) }\end{array}$ & - \\
\hline Hm_Cnt & Experimental human dentin posts (EHDP) & No sterilization. \\
\hline Hm_Aut & EHDP & Steam autoclaving (Kronos B; Newmed) at $121^{\circ} \mathrm{C}$ for $15 \mathrm{~min}$. \\
\hline $\mathrm{Hm}-\mathrm{Rad}$ & EHDP & $\begin{array}{l}\text { Gamma radiation (Radiating over the course of } 5 \text { days with a cobalt- } 60 \\
\text { source with a radiation cycle of } 3.4 \mathrm{~Gy} / \mathrm{min} \text {, resulting in an overall dose } \\
\text { of approximately } 25 \mathrm{kGy} \text { ). }\end{array}$ \\
\hline Bv_Cnt & Experimental bovine dentin posts (EBDP) & No sterilization. \\
\hline Bv_Aut & EBDP & Steam autoclaving (Kronos B; Newmed) at $121^{\circ} \mathrm{C}$ for $15 \mathrm{~min}$. \\
\hline Bv_Rad & EBDP & $\begin{array}{l}\text { Gamma radiation (Radiating over the course of } 5 \text { days with a cobalt- } 60 \\
\text { source with a radiation cycle of } 3.4 \mathrm{~Gy} / \mathrm{min} \text {, resulting in an overall dose } \\
\text { of approximately } 25 \mathrm{kGy} \text { ). }\end{array}$ \\
\hline
\end{tabular}

Table 2. Mean and SD of PBS values and differences between post type/sterilization method groups.

\begin{tabular}{ccccccc}
\hline Post Type & \multicolumn{2}{c}{ Fb } & \multicolumn{2}{c}{ Hm } & \multicolumn{2}{c}{ Bv } \\
\hline $\begin{array}{c}\text { Sterilization } \\
\text { Method }\end{array}$ & Mean \pm SD & Differences & Mean \pm SD & Differences & Mean \pm SD & Differences \\
\hline Cnt & $12.36 \pm 1.54$ & $\mathrm{~A}$ & $11.06 \pm 1.38$ & $\mathrm{Aa}$ & $9.42 \pm 1.31$ & $\mathrm{Ba}$ \\
Rad & & & $9.19 \pm 0.86$ & $\mathrm{Ab}$ & $7.92 \pm 0.96$ & $\mathrm{Ab}$ \\
Aut & & & $9.37 \pm 1.24$ & $\mathrm{Ab}$ & $7.97 \pm 0.86$ & $\mathrm{Bb}$ \\
\hline
\end{tabular}

*Mean values represented with same uppercase letters (row) or lowercase letters (column) are not significantly different according to TukeyHSD multiple comparison test $(\mathrm{P}<.001)$.

SEM: Standart error mean

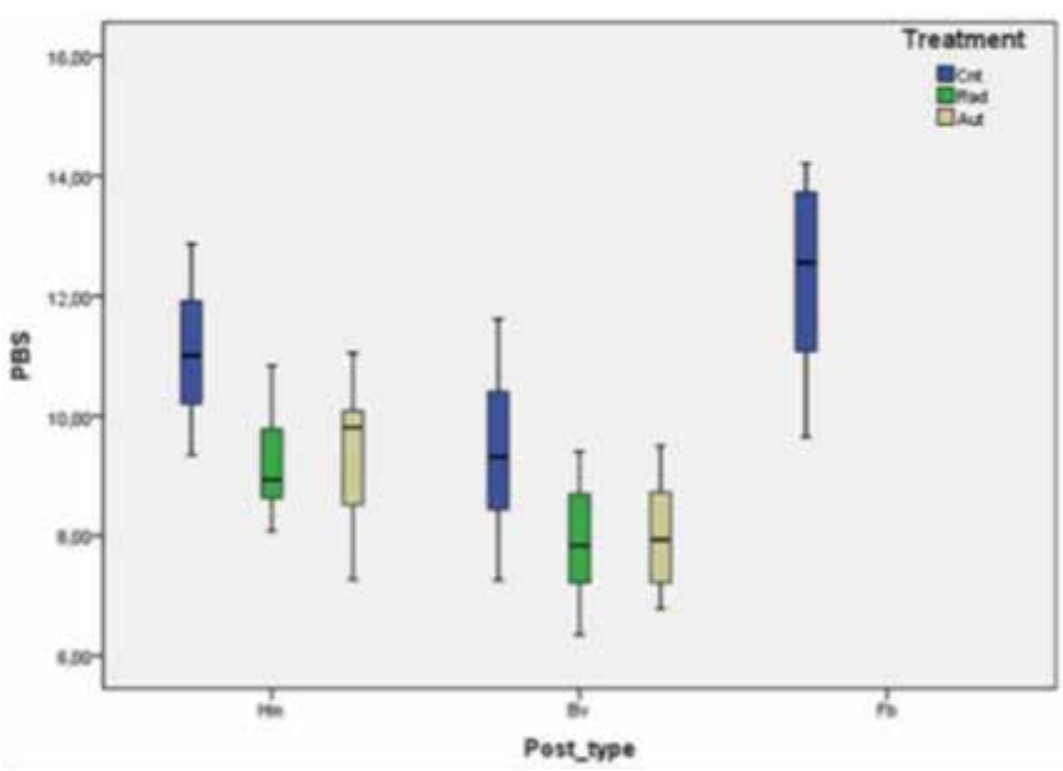

Figure 3. Interval plot of mean push-out bond strength values $(\mathrm{N})$ according to the groups. 
Table 3. Frequencies of different fracture types for test groups.

\begin{tabular}{cccccccc}
\hline $\begin{array}{c}\text { Groups } \\
\text { Fracture } \\
\text { Type }\end{array}$ & Fb_Cnt & Hm_Cnt & Hm_Rad & Hm_Aut & Bv_Cnt & Bv_Rad & Bv_Aut \\
\hline Adhesive & 2 & 2 & 6 & 4 & 2 & 7 & 7 \\
Mixed & 5 & 3 & 6 & 6 & 6 & 5 & 5 \\
Cohesive & 5 & 7 & 0 & 2 & 4 & 0 & 0 \\
\hline
\end{tabular}
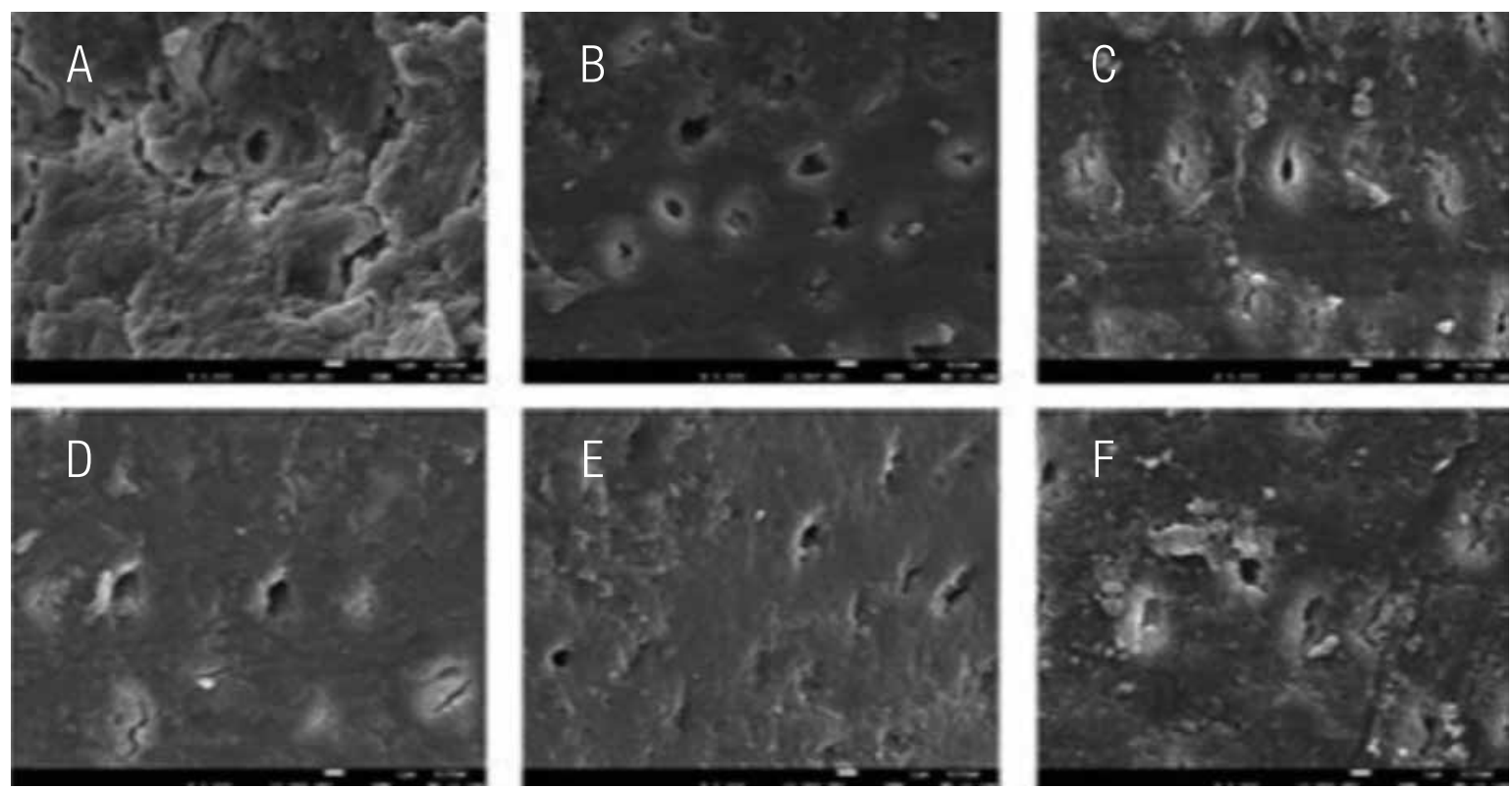

Figure 4. Representative scanning electron micrographs of experimental dentin posts' surfaces. A, Group Hm_Cnt specimen. B, Group Hm_Aut specimen. C, Group Hm_Rad specimen. D, Group Bv_Cnt specimen. E, Group Bv_Aut specimen. F, Group Bv_Rad specimen (original magnification $\times 5000$ ).

\section{DISCUSSION}

From the results of this in vitro study, both null hypotheses were rejected. Because, not only significant differences obtained between glass fiber posts and EDPs, but also both sterilization methods affect the PBS of dentin posts.

GFP has become golden standard for the rehabilitation of excessively damaged teeth, because of successful results in terms of aesthetic, biomechanical properties with significantly reduced failure rates (Akkayan and Gülmez, 2002) (16).
Therefore, in the present study a GFP system was considered as the control group to compare with the EDP groups in terms of PBS and failure modes. In the present study, the $\mathrm{Fb}$ group showed the highest PBS value. This could be attributed to the composition of fiber posts in which unidirectional glass fibers embedded in an epoxy resin matrix. Because the bonding capacity of this resin content is higher than the bonding capacity of the dentin post to the resin cement.

One of the primary aims of this study was to compare the PBS values between bovine and 
human EDPs. It has been revealed that the PBS values of human EDPs were significantly higher than bovine EDPs. This study also aimed to evaluate each sterilization method's effect on the PBS of the dentin posts, since the biological dentin post materials must be sterilized before placing into the rooth canal (4). Gamma radiation has been used successfully to sterilize the allograft materials as well as medical devices and food marketing (17). According to the results of the present study, the gamma radiation showed significantly lower PBS values than the no sterilization groups, regardless of the type of EDPs.

In the present study, the PBS values of both human and bovine EDPs ranged between 7.9-11 MPa, which agrees with Zicari et al. (18). Additionally, the results of the present study was in agreement with those obtained by Galhano et al. who revealed higher PBS values in human root dentin than in bovine root dentin (19). This could be related to differences between human and bovine teeth pertaining to their size, number, tubule orientation, and degree of intra-tubular mineralization (20). The SEM images included in the present study also corroborate these results (Figure 4). With respect to the SEM images, the human-root dentin seems (Figure 4A,4B,4C) to have a higher density of dentinal tubules and larger tubule diameter than the bovine-root dentin (Figure 4D,4E,4F). This may explain the higher PBS values that the present study observed in human EDP groups than the bovine EDP groups. However, Sano et al. found no significant differences between human and bovine teeth with regard to the ultimate tensile strength and modulus of elasticity of both mineralized and demineralized dentin (15).

In the present study, both steam autoclaving and gamma radiation negatively affected the PBS values of the human and bovine dentin posts. Jiang et al. found that autoclaving caused collagen denaturation and coagulation resulting decreased dentin permeability (21). On the contrary, White et al. found that gamma radiation had no effect on dentin permeability or structure; however, they reported that autoclave sterilization induced a loss of mineral and collagen components from the surface, with a change in the mineral component (13). This may explain the decrease in the PBS values of autoclaved groups in the present study. Because elevated temperatures and a high level of moisture could be detrimental to adhesion capacity of EDPs.

Sperandio et al. concluded that sterilization with gamma radiation at $25 \mathrm{kGy}$ (the typical dose used to sterilize hospital supplies) did not affect the shear bond strength of human tooth dentin (22). Although the same dose of gamma radiation was applied in the present study, significant decreases were detected in the PBS values of both human and bovine dentin posts. This difference can be attributed to differences in the studies' methodologies.

Cheung et al. demonstrated that sterilization with gamma radiation may cause molecular fragmentation via chain scission of the collagen peptide chains (23). This molecular fragmentation may be responsible for the decreased PBS values that the present study found in the gamma radiation-sterilized EDPs (both human and bovine). Furthermore, the SEM analysis included in the present study revealed generalized micromorphological alterations on the radiated dentin surfaces (Figure 4). These alterations may have been caused by the degradation of the collagen fibers network. Additionally, the bonding capacity of the radiated root dentin posts to the resin cement could interfere with the apparent degradation of the organic portion of dentin. With respect to the failure modes, there was no cohesive fracture type in radiated groups which means a poor bonding capacity between the radiated EDP and the resin cement.

Recently, the use of biological materials in restorations has become more common, which has 
resulted in a need for more extensive in vitro and in vivo studies similar to the present study. This study suggests that human teeth may be utilized as a biological dentin post material when it could be obtained autogenously. However, bovine dentin posts were not as effective as human dentin posts, unsterile bovine dentin posts showed similar results to the sterile human dentin posts with regard to the PBS to the root dentin in this study. So, further studies evaluating bovine or human dentin posts with different parameters are needed before they can serve as an alternative post material.

\section{CONCLUSION}

Despite the constraints of the present in vitro study, its findings depict that:

- Gamma radiation and steam autoclaving negatively affect the PBS values of EDPS.

- The human EDPs show generally higher PBS values than the bovine EDPS.

ACKNOWLEDGEMENT

The authors report no conflicts of interest related to this study.

\section{CONFLICT OF INTEREST}

The authors declare that they have no conflict of interest.

\section{REFERENCES}

1. Kathuria A., Kavitha M., Khetarpal S. Ex vivo fracture resistance of endodontically treated maxillary central incisors restored with fiberreinforced composite posts and experimental dentin posts. J Conserv Dent 2011; 14: 401-5.

2. Ambica K., Mahendran K., Talwar S., Verma M., Padmini G., Periasamy R. Comparative evaluation of fracture resistance under static and fatigue loading of endodontically treated teeth restored with carbon fiber posts, glass fiber posts, and an experimental dentin post system: an in vitro study. J Endod 2013;39: 96-100.

3. Diana H. H., Oliveira J. S., Ferro M. C. D. L., Silva-Sausa Y. T., Gomes E. A. Stress distribution in roots restored with fiber posts and an experimental dentin post: 3D-FEA. Braz Dent J 2016; 27: 223-227.

4. Swarupa C.H., Sajjan G. S., Bhupahupathiraju V. L., Anwarullahwarullah A., Sashikanth V. Y. Biological dentin post for intra radicular rehabilitation of a fractured anterior tooth. $\mathrm{J}$ Clin Diagn Res 2014; 8: 242-243.

5. Kumar B. S., Kumar S., Mohan Kumar N. S., Karunakaran J. V. Biological post. J Pharm Bioallied Sci 2015; 7: 721-724.

6. Soares C. J., Rodrigues M. P., Faria-E-Silva A. L. et al. How biomechanics can affect the endodontic treated teeth and their restorative procedures? Braz Oral Res 2018;32: 169-183.

7. Sculean A., Windisch P., Chiantella G. C. Human histologic evaluation of an intrabony defect treated with enamel matrix derivative, xenograft, and GTR. Int $\mathrm{J}$ Periodontics Restorative Dent 2004; 24: 326-333.

8. ArRejaie A., Al-Harbi F., Alagl A. S., Hassan K. S. Platelet-rich plasma gel combined with bovine-derived xenograft for the treatment of dehiscence around immediately placed conventionally loaded dental implants in humans: Cone beam computed tomography and three-dimensional image evaluation. Int $\mathrm{J}$ Oral Maxillofac Implants 2016; 31: 431-438.

9. Yassen G. H., Platt J. A., Hara A. T. Bovine teeth as substitute for human teeth in dental research: a review of literature. J Oral Sci 2011; 53: 273-272.

10. Tagami J., Tao L., Pashley D. H., Horner J. A. The permeability of dentine from bovine incisors in vitro. Arch Oral Biol 1989;34: 773-777. 
11. Tate W. H., White R. R. Disinfection of human teeth for education purposes. J Dent Educ 1991; 55: 583-585.

12. Pantera E. A., Schuster GS. Sterilization of extracted human teeth. J Dent Educ 1990; 54 : 283-285.

13. White J. M., Goodis H. E., Marshall S. J., Marshall G. W. Sterilization of teeth by gamma radiation. J Dent Res 1994; 73: 1560-1567.

14. Brauer D. S., Saeki K., Hilton J. F., Marshall G. W., Marshall S. J. Effect of sterilization by gamma radiation on nano-mechanical properties of teeth. Dent Mater 2008; 24: 1137-40.

15. Sano H., Ciucchi B., Matthews W. G., Pashley DH. Tensile properties of mineralized and demineralized human and bovine dentin. J Dent Res 1994; 73: 1205-1211.

16. Akkayan B., Gülmez T. Resistance to fracture of endodontically treated teeth restored with different post systems. J Prosthet Dent 2002; 87: 431- 437.

17. Vastel L., Meunier A., Siney H., Sedel L., Courpied J. P. Effect of different sterilization processing methods on the mechanical properties of human cancellous bone allografts.

Biomaterials 2004; 25: 2105-2110.
18. Zicari F., De Munck J., Scotti R., Naert I., Van Meerbeek B. Factors affecting the cement-post interface. Dent Mater 2012; 28: 287- 297.

19. Galhano G., Melo R. M., Valandro L. F., Bottino M. A. Comparison of resin push-out strength to root dentin of bovine- and humanteeth. Indian Dent Res 2009; 20: 332- 336.

20. Schilke R., Lisson J. A., Bauss O., Geurtsen W. Comparison of the number and diameter of dentinal tubules in human and bovine dentine by scanning electron microscopic investigation. Arch Oral Biol 2000; 45: 355- 361.

21. Jiang R., Xu Y., Lin H. Effects of two disinfection/sterilization methods for dentin specimens on dentin permeability. Clin Oral Investig 2019; 23: 899-904.

22. Sperandio M., Souza J. B., Oliveria D. T. Effect of gamma radiation on dentin bond strength and morphology. Braz Dent J 2001; 12: 205-208.

23. Cheung D. T., Perelman N., Tong D., Nimni M. E. The effect of gamma-irradiation on collagen molecules, isolated alpha-chains and crosslinked native forces. J Biomed Mater Res 1990; 24: 581- 589. 